\title{
Axillary lymph node metastasis from papillary thyroid carcinoma with elevated CA 19-9 and CA 242 levels: a case report and literature review
}

\author{
Yeqin Ni ${ }^{1 \#}$, Yu Zhang ${ }^{2 \#}$, Kaili Xiang ${ }^{1}$, Pan Zhao ${ }^{3}$, Gang Pan ${ }^{2}$, You Peng ${ }^{2}$, Jingjing Shi ${ }^{2}$, Li Zhou ${ }^{2}$, \\ Linlin $\mathrm{Mao}^{2}$, Dingcun $\mathrm{Luo}^{2} \wedge$ \\ ${ }^{1}$ The Fourth Clinical Medical College, Zhejiang Chinese Medical University, Hangzhou, Chinaa; ${ }^{2}$ Department of Surgical Oncology, Affiliated \\ Hangzhou First People's Hospital, Zhejiang University School of Medicine, Hangzhou, China; ${ }^{3}$ Department of Pathology, Affiliated Hangzhou First \\ People's Hospital, Zhejiang University School of Medicine, Hangzhou, China \\ \#These authors contributed equally to this work. \\ Correspondence to: Dingcun Luo. Department of Surgical Oncology, Affiliated Hangzhou First People's Hospital, Zhejiang University School of \\ Medicine, No. 261, Huansha Road, Shangcheng district, Hangzhou 310006, China. Email: 1dc65@163.com.
}

\begin{abstract}
Axillary lymph node metastasis is a rare event in thyroid carcinoma. The simultaneous expression of carbohydrate antigens 19-9 (CA 19-9) and 242 (CA 242) in thyroid tumors is also extremely rare. Herein, we report a case of axillary lymph node metastasis with elevated serum CA 19-9 and CA 242 in papillary thyroid carcinoma. In a 47-year-old woman with thyroid carcinoma, masses developed in the neck and axilla over a two-month period, which were surgically treated using total thyroidectomy, with neck and axillary lymph node dissection. Histopathological examination confirmed a diffuse sclerosing variantpapillary thyroid carcinoma, with 52 of 63 axillary lymph node metastases. Notably, serum CA 19-9 and CA 242 levels decreased from the initial values of 1,110 and $50 \mathrm{kU} / \mathrm{L}$, respectively, to normal levels one month postoperatively and have remained stable for two years since. The aggressive biological behavior of diffuse sclerosing variant-papillary thyroid carcinoma and the abnormal anatomical distortion caused by tumors in this case most likely reflect the mechanisms underlying retrograde dissemination in lymphatic tubes. However, the mechanism leading to a simultaneous elevation of CA 19-9 and CA 242 secreted by the diffuse sclerosing variant-papillary thyroid carcinoma has not been elucidated. The patient has survived for two years suggesting that timely surgery can help such patients achieve a better prognosis.
\end{abstract}

Keywords: Diffuse sclerosing variant-papillary thyroid carcinoma (DSV-PTC); axillary lymph node metastasis (ALNM); carbohydrate antigens; case report

Submitted Nov 13, 2020. Accepted for publication Jan 04, 2021.

doi: $10.21037 / g s-20-815$

View this article at: http://dx.doi.org/10.21037/gs-20-815

\section{Introduction}

Papillary thyroid carcinoma (PTC) has an indolent course and a reasonably good prognosis, with 10 -year cancerspecific survival greater than $90 \%$ (1). However, diffuse sclerosing variant-PTC (DSV-PTC), a major histologic subtype of PTC, accounts for approximately $0.5-5.3 \%$ of all the PTC cases and often exhibits more aggressive characteristics, such as larger tumor size, extrathyroidal extension, and extensive lymph node metastasis (LNM), compared to typical PTC (2). The incidence of LNM may be present in $30-80 \%$ of patients at the time of diagnosis,

^ ORCID of Yeqin Ni: 0000-0001-9575-4910; Dingcun Luo: 0000-0002-7320-4202. 

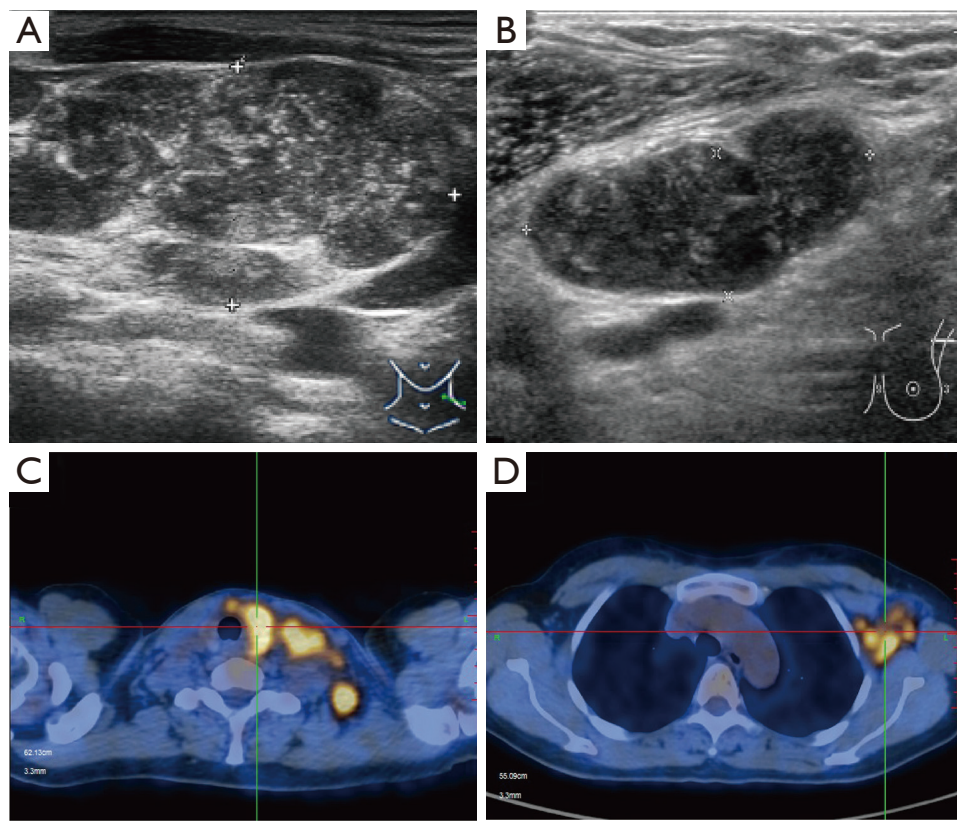

$E$

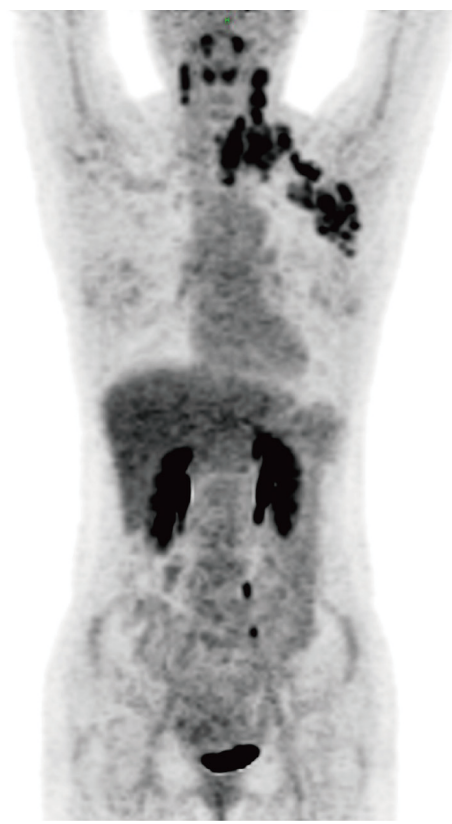

Figure 1 Preoperative imageological data. Ultrasound images: (A) diffuse calcifications, irregular shapes, and obscure boundary are seen in the left thyroid lobe, $4.3 \mathrm{~cm} \times 2.3 \mathrm{~cm} \times 3.5 \mathrm{~cm}$ in size; (B) a hypoechoic, large, and multinodular confluent mass found in the left axillary region, $3.2 \mathrm{~cm} \times 3.0 \mathrm{~cm} \times 2.0 \mathrm{~cm}$ in size. ${ }^{18} \mathrm{~F}$-FDG PET/CT images: (C) hypermetabolic FDG accumulation in thyroid corresponding to (A) images; (D) hypermetabolic FDG accumulation in left axilla corresponding to (B) images; (E) whole body metabolism images.

which is a risk factor for local recurrence (3). In particular, axillary lymph node metastasis (ALNM) indicates a poor prognosis when combined with multi-organ metastasis $(4,5)$. Since Mizukami et al. (6) first reported ALNM in thyroid cancer in 1993, a total of 23 cases have been reported in the literature to date.

Carbohydrate antigen (CA), such as CA 19-9, have been widely utilized for gastrointestinal malignancy screening since their discovery for colorectal tumors by Koprowski in 1979 (7). However, carbohydrate antigenbased screening is not the "gold standard" for any special tumor. Recent clinical investigations have shown that carbohydrate antigen levels can also be elevated in other systemic disorders such as lung cancer, pulmonary sequestration, and hepatobiliary diseases $(8,9)$. To the best of our knowledge, high serum CA 19-9 and CA 242 levels rarely occur in thyroid cancers.

Herein, we briefly present a case of ALNM from DSVPTC with elevated CA 19-9 and CA 242. We extensively reviewed all related reports, aiming to improve our understanding of this disease. Here, we present the following case in accordance with the CARE reporting checklist (available at http://dx.doi.org/10.21037/gs-20-815).

\section{Case presentation}

A 47-year-old woman presented with a mass in the left neck that had developed 2 months prior, with no previous radiological exposure and family history. Physical examination was normal except for multiple hard masses palpated in the neck and left axilla. Ultrasound revealed diffuse calcification and hypoechoic nodules in the thyroid, with a TI-RADS 5 classification, highly suggestive of malignancy (Figure 1A). Additionally, multiple enlarged lymph nodes were found to be fused together in the neck, bilaterally, and in the left axilla (Figure 1B). Contrastenhanced computed tomography (CT) identified multiple nodules with heterogeneous reinforcement, which also appeared on ${ }^{18} \mathrm{~F}$-fluorodeoxyglucose positron emission tomography/computed tomography $\left({ }^{18} \mathrm{~F}-\mathrm{FDG} \mathrm{PET} / \mathrm{CT}\right)$, with diffuse hypermetabolic FDG accumulation (Figure $1 C, D, E)$. There was no evidence of any malignant lesions in the lungs, breast, and gastrointestinal regions. The patient underwent gastrointestinal endoscopies to exclude the possibility of digestive malignancies. Serum CA 19-9 and CA 242 levels were elevated to 1,110.0 kU/L (normal $<37 \mathrm{kU} / \mathrm{L}$ ) and $50 \mathrm{kU} / \mathrm{L}$ (normal $<20 \mathrm{kU} / \mathrm{L}$ ), respectively. 

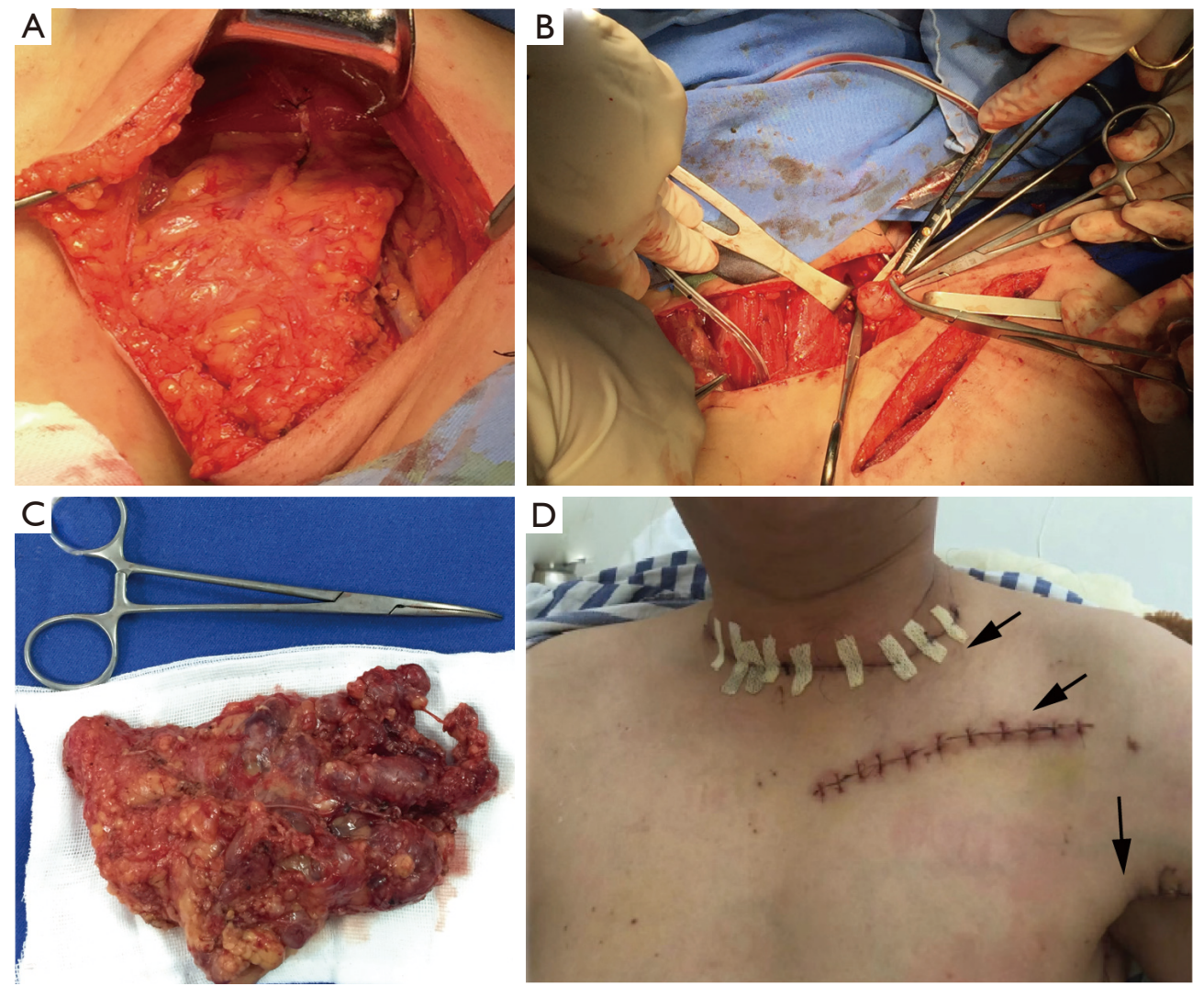

Figure 2 The surgeon individually customized a three-incision treatment for the patient. (A, B) Intraoperative views of the three incisions: the left axillary, the neck and the left supraclavicular; (C) surgical specimen of left axillary lymph nodes; (D) postoperative view of the incisions.

Levels of thyroid peroxidase antibodies (TPO-Ab) and thyroglobulin antibodies (TG-Ab) were elevated to $1,300 \mathrm{kU} / \mathrm{L}$ (normal $<60 \mathrm{kU} / \mathrm{L}$ ) and $325.6 \mathrm{kU} / \mathrm{L}$ (normal $<60 \mathrm{kU} / \mathrm{L}$ ), respectively.

The origin of the axillary mass remained unclear until biopsy and immunohistochemistry (IHC) examination, which confirmed ALNM from the thyroid neoplasm. Thereafter, the patient underwent total thyroidectomy (TTx) and bilateral modified neck dissection combined with left supraclavicular and axillary lymph node dissection (ALND) (Figure 2). The histopathological report revealed a $5.5 \mathrm{~cm}$ DSV-PTC invading into the striated muscles, with metastatic malignancies in 18 of the 45 cervical lymph nodes (CLNs) and in 52 of the 63 axillary lymph nodes (ALNs) (Figure 3). According to the 8th revision of the TNM staging system (10), the patient was classified as T3bN1bM1, stage II. While neither BRAFV600E mutation nor RET/PTC rearrangement were detected by Next Generation Sequencing, the malignancies were positive for

\section{TP53 mutation.}

Postoperatively, TG-Ab was still positive, but it dropped down to $90.6 \mathrm{kU} / \mathrm{L}$ one month later. Serum thyroglobulin level $(\mathrm{Tg})$ was maintained under $0.04 \mathrm{U} / \mathrm{mL}$ in thyroid stimulating hormone-suppressive doses. The stimulated $\mathrm{Tg}$ level (sTg) was $1.72 \mathrm{U} / \mathrm{mL}$ before the patient received 131 iodine $\left({ }^{131} \mathrm{I}\right)$ radiotherapy at $100 \mathrm{mCi}$ with a poor response; the ${ }^{131} \mathrm{I}$ scan showed no abnormal uptake throughout the whole body. The patient was followed-up with regular observation due to the advanced disease but developed regional recurrences at the 5 th and 8 th months after the first operation, respectively. Ultrasound detected the suspicious lymph nodes in the non-operated areas, involving the bilateral neck, where no abnormalities were found in the preoperative imaging examinations, and the biopsy confirmed lymph node recurrence, both of which were managed by therapeutic surgery.

It is worth noting that the serum CA 19-9 and CA 242 levels dramatically declined to $510.8 \mathrm{kU} / \mathrm{L}$ and 38.3 

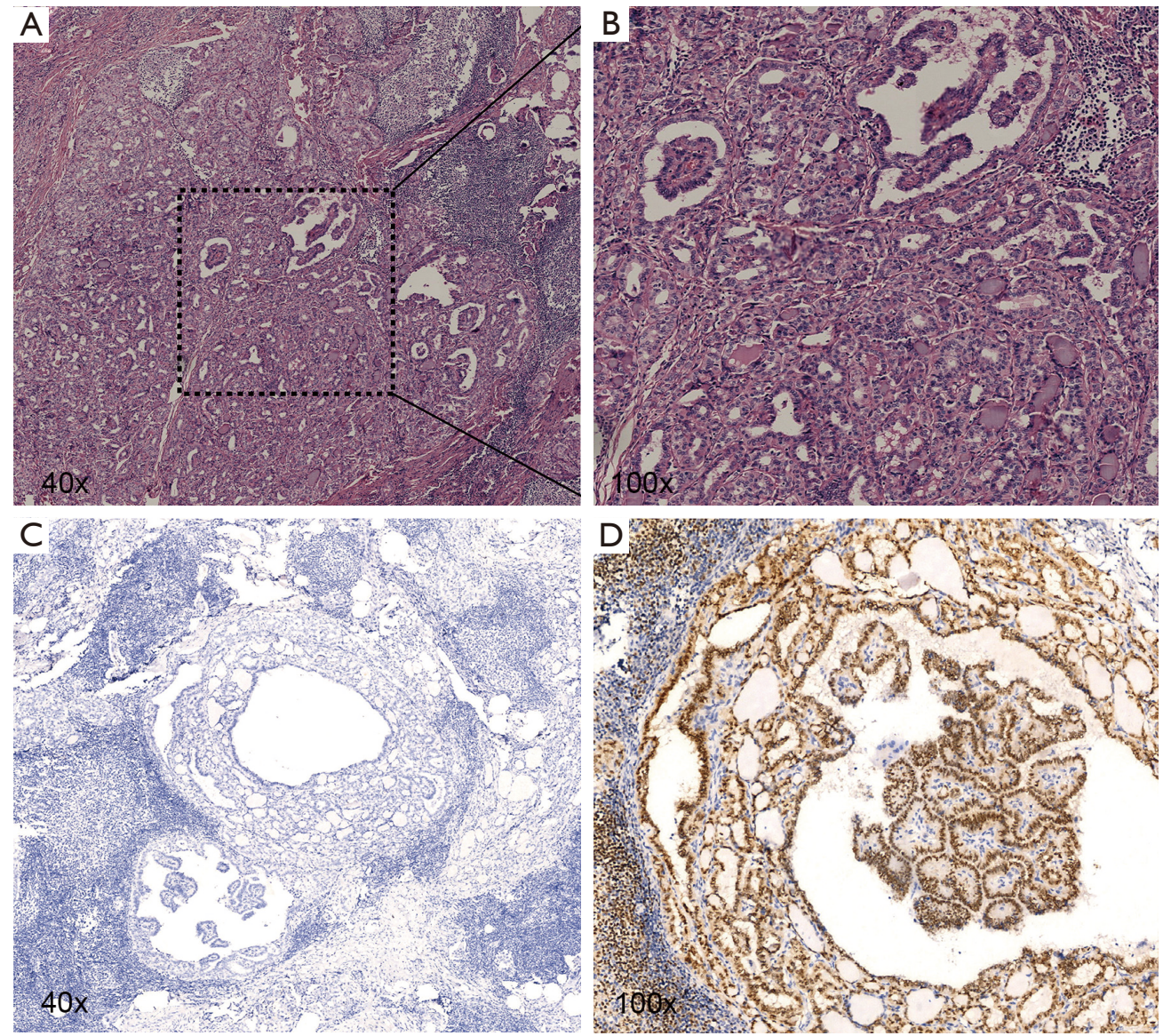

Figure 3 The pathologic microphotograph of thyroid tumor. (A,B) HE staining shows diffuse sclerosing variant-papillary thyroid carcinoma (magnification 40×, 100x). (C) Negative immunohistochemistry staining for CA 19-9 (magnification 40×). (D) Positive immunohistochemistry staining for PAX8 (magnification 100x).

$\mathrm{kU} / \mathrm{L}$, respectively, 1 day after the initial surgery. They returned to normal levels 2 month later and have remained stable over the two-year follow-up, despite two regional recurrences during survival with disease (Figure $4 A$ ). Similarly, $\mathrm{Tg}$ and $\mathrm{Tg}$-Ab showed a continuous downward trend postoperatively, indicating that these indexes may no longer be of significance in monitoring the recurrence status (Figure 4B). All procedures performed in this study involving human participants were in accordance with the ethical standards of the institutional committee, and with the Helsinki Declaration (as revised in 2013). Written informed consent was obtained from the patient.

\section{Discussion}

In patients with ALNM, evaluating the pathological nature of the ALNs and tracing the origin of the primary tumor are the principal concerns for clinicians. ALNs are common metastatic areas for breast cancers and pulmonary neoplasms, the possibilities of which need to be excluded. Abnormally high serum CA 19-9 and CA 242 levels, however, suggest the possibility of additional digestive malignancies.

The mechanism of ALNM in thyroid neoplasms has not been elucidated; however, it is probably associated with the biological behavior of DSV-PTC and the anatomical structure of the neck. First, invasion and metastasis are features of DSV-PTC. Cherean et al. (11) demonstrated that the rate of LNM in patients with DSV-PTC (80.3\%) was higher than that in patients with typical PTC (48.9\%, $\mathrm{P}<0.01)$. In addition, the 10 -year recurrence-free survival in DSV-PTC was only $57.5 \%$ (12). In this case, the surgeon observed intraoperatively that the tumor had invaded the surrounding striated muscles and tissues. The area of LNM 

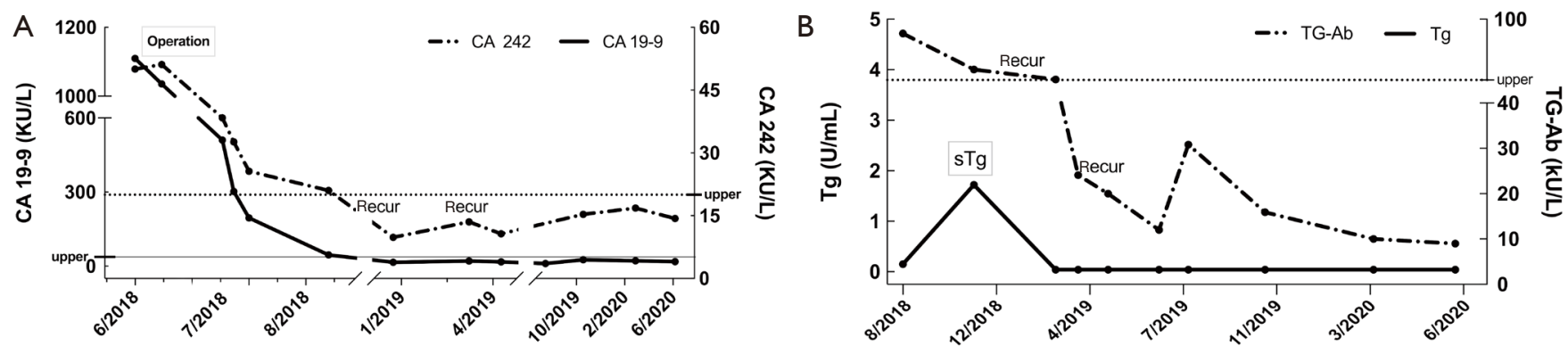

Figure 4 The timeline figures of (A) serum CA 19-9 and CA 242 levels and (B) TG-Ab and Tg levels.

was extensively distributed across the six cervical levels, from I to VI. The number of LNMs reached 70, with the longest diameter of metastatic foci being greater than $3 \mathrm{~cm}$. It is notable that the TP53 mutation, which is predominantly altered in anaplastic thyroid carcinoma, was detected in the primary lesion, explaining both its aggressive behavior and reduced iodine uptake (13). Second, the normal neck lymphatic circulation is centripetal in nature, with the jugular and subclavian lymphatic trunk merging into the thoracic duct and injecting into the venous angle. When a tumor invades the venous angle along the lymphatic ducts or when there is regional tissue fibrosis caused by previous surgery and radiotherapy, there is destruction of normal anatomical structures, causing compression and blockage in the lymphatic circulation. This could result in retrograde dissemination of the tumor cells to the supraclavicular and axillary areas $(14,15)$.

There are 23 cases of thyroid neoplasms metastasizing to ALNs reported in the literature (Table S1). Of these, PTC was the most common type with 14 cases, including various pathological subtypes, such as tall-cell $(15)$, follicular $(5,16)$, and poorly differentiated types $(4,14)$. Of the total, six patients developed ALNM at the time of diagnosis and 17 patients presented with recurrences many years later. The progression of metastases is obscure and undetectable, with a median time of recurrence of 6 years and a maximum of 20 years (17). Patients with additional distant metastases represented $73.9 \%$ of the cases, including metastases to the mediastinum (10 cases, $43.5 \%$ ), lung ( 8 cases, $34.8 \%$ ), bone ( 4 cases, $17.4 \%$ ), liver ( 2 cases, $6.7 \%$ ), and breast ( 2 cases, $6.7 \%$ ). Most scholars believe that surgery combined with adjuvant therapy is the most effective treatment for ALNM in thyroid malignancies. Early surgical procedures, including TTx and ALND, following early detection, may significantly improve the quality of life and reduce recurrences. Krishnamurthy et al. (15) recommended external beam radiotherapy for the axillary region, and Cummings et al. (5) and Ozdemir et al. (18) chose targeted therapy and chemotherapy as alternatives for advanced distant metastases. However, the therapeutic effect of these interventions has not been confirmed. According to the 8th revision of the TNM staging system (10), the patient in our case was classified as T3bN1bM1, stage II. Owing to the early personalized therapy provided, the patient survived disease-free during the two years of follow-up.

Elevated levels of CA 19-9 and CA 242, which have a high specificity for pancreatic cancer and hepatobiliary disease, are extremely rare in PTC, and the mechanism underlying the elevation of these antigens still needs to be explored. Some authors have speculated that it may be caused by the anaplasia of PTC cells. Once the tumor is dedifferentiated, it may indicate a poor prognosis. In a reported case of PTC with lung metastasis, the metastatic tumor cells showed poorly differentiated morphology, and serum CA 19-9 levels were observed to increase with the progression of lung metastases and, subsequently, to decrease after regional lung resection (19). A case reported by Yamaguchi et al. (20) showed that serum CA 19-9 levels increased to $2,228 \mathrm{pg} / \mathrm{mL}$ with rapid spread to the whole body; postmortem examination hypothesized that extensive undifferentiated lesions in the thorax and peritoneum could be the source of CA 19-9. Interestingly, in the present case, IHC for CA 19-9 showed negative results in primary lesions and axillary metastasis foci, with no tissue showing anaplasia (Figure 3). The halftime of the carbohydrate antigen is approximately 14 h (9). Correspondingly, serum CA 19-9 and CA 242 levels declined by half on the day after surgery, fell to normal levels in the first month, and remained stable for up to two years of follow-up, indicating that the CA 19-9-derived lesion had been completely removed. After ruling out common sources of digestive tract malignancies, 
we concluded that the antigens originated from the DSV-PTC.

In conclusion, this is the first report of elevated serum CA 19-9 and CA 242 levels in a patient with DSV-PTC and ALNM. This case indicates that CA 19-9 and CA 242 are not specific markers of digestive cancers and could be potential diagnostic markers for a particular type of thyroid carcinoma. In addition, an understanding of the mechanism of ALNM in PTC will clarify the correlation between the biological behavior of the tumor and the anatomy. Finally, diagnostic modalities, such as ultrasound and CT, and timely treatment may be of significance in improving prognosis.

\section{Acknowledgments}

The authors are grateful to all members of the Department of Surgical Oncology, at Hangzhou First People's Hospital. Funding: This work was supported by the Key Project of Scientific and Technological Innovation in Hangzhou [20131813A08]; Applied Research Project of Commonweal Technology in Zhejiang Province [2017C33180]; Science Research Program of Hangzhou [20180533B39]; and the Project of Medical Scientific and Technology Program in Hangzhou [A20200432].

\section{Footnote}

Reporting Checklist: The authors have completed the CARE reporting checklist. Available at http://dx.doi.org/10.21037/ gs-20-815

Peer Review File: Available at http://dx.doi.org/10.21037/gs20-815

Conflicts of Interest: All authors have completed the ICMJE uniform disclosure form (available at http://dx.doi. org/10.21037/gs-20-815). The authors have no conflicts of interest to declare.

Ethical Statement: The authors are accountable for all aspects of the work in ensuring that questions related to the accuracy or integrity of any part of the work are appropriately investigated and resolved. All procedures performed in this study involving human participants were in accordance with the ethical standards of the institutional committee, and with the Helsinki Declaration (as revised in 2013). Written informed consent was obtained from the patient for publication of this manuscript and any accompanying images.

Open Access Statement: This is an Open Access article distributed in accordance with the Creative Commons Attribution-NonCommercial-NoDerivs 4.0 International License (CC BY-NC-ND 4.0), which permits the noncommercial replication and distribution of the article with the strict proviso that no changes or edits are made and the original work is properly cited (including links to both the formal publication through the relevant DOI and the license). See: https://creativecommons.org/licenses/by-nc-nd/4.0/.

\section{References}

1. Tam S, Boonsripitayanon M, Amit M, et al. Survival in Differentiated Thyroid Cancer: Comparing the AJCC Cancer Staging Seventh and Eighth Editions. Thyroid 2018;28:1301-10.

2. Malandrino P, Russo M, Regalbuto C, et al. Outcome of the Diffuse Sclerosing Variant of Papillary Thyroid Cancer: A Meta-Analysis. Thyroid 2016;26:1285-92.

3. Jianyong L, Jinjing Z, Zhihui L, et al. A Nomogram Based on the Characteristics of Metastatic Lymph Nodes to Predict Papillary Thyroid Carcinoma Recurrence. Thyroid 2018;28:301-10.

4. Koike K, Fujii T, Yanaga H, et al. Axillary lymph node recurrence of papillary thyroid microcarcinoma: report of a case. Surg Today 2004;34:440-3.

5. Cummings AL, Goldfarb M. Thyroid carcinoma metastases to axillary lymph nodes: report of two rare cases of papillary and medullary thyroid carcinoma and literature review. Endocr Pract 2014;20:e34-7.

6. Mizukami Y, Nakajima H, Annen Y, et al. Mucinproducing poorly differentiated adenocarcinoma of the thyroid. A case report. Pathol Res Pract 1993;189:608-12; discussion 612-5.

7. Koprowski H, Steplewski Z, Mitchell K, et al. Colorectal carcinoma antigens detected by hybridoma antibodies. Somatic Cell Genet 1979;5:957-71.

8. Scarà S, Bottoni P, Scatena R. CA 19-9: Biochemical and Clinical Aspects. Adv Exp Med Biol 2015;867:247-60.

9. Tsen A, Barbara M, Rosenkranz L. Dilemma of elevated CA 19-9 in biliary pathology. Pancreatology 2018;18:862-7.

10. Amin MB, Edge S, Greene F, et al. AJCC Cancer Staging Manual 8th edition. Springer International; 2017.

11. Chereau N, Giudicelli X, Pattou F, et al. Diffuse Sclerosing 
Variant of Papillary Thyroid Carcinoma Is Associated With Aggressive Histopathological Features and a Poor Outcome: Results of a Large Multicentric Study. J Clin Endocrinol Metab 2016;101:4603-10.

12. Kim SK, Park I, Woo JW, et al. Follicular and Diffuse Sclerosing Variant Papillary Thyroid Carcinomas as Independent Predictive Factors of Loco-Regional Recurrence: A Comparison Study Using Propensity Score Matching. Thyroid 2016;26:1077-84.

13. Yoo SK, Song YS, Lee EK, et al. Integrative analysis of genomic and transcriptomic characteristics associated with progression of aggressive thyroid cancer. Nat Commun 2019;10:2764.

14. Nakayama H, Wada N, Masudo Y, et al. Axillary lymph node metastasis from papillary thyroid carcinoma: report of a case. Surg Today 2007;37:311-5.

15. Krishnamurthy A, Vaidhyanathan A. Axillary lymph node metastasis in papillary thyroid carcinoma: report

Cite this article as: Ni Y, Zhang Y, Xiang K, Zhao P, Pan G, Peng Y, Shi J, Zhou L, Mao L, Luo D. Axillary lymph node metastasis from papillary thyroid carcinoma with elevated CA 19-9 and CA 242 levels: a case report and literature review. Gland Surg 2021;10(3):1147-1153. doi: 10.21037/gs-20-815 of a case and review of the literature. J Cancer Res Ther 2011;7:220-2.

16. Damle N, Singh H, Soundararajan R, et al. Radioiodine avid axillary lymph node metastasis in papillary thyroid cancer: report of a case. Indian J Surg Oncol 2011;2:193-6.

17. Kepenekci I, Demirkan A, Cakmak A, et al. Axillary lymph node metastasis as a late manifestation of papillary thyroid carcinoma. Thyroid 2009;19:417-9.

18. Ozdemir M, Makay O, Simsir I, et al. Medullary carcinoma of the thyroid with axillary metastasis: a case report. Int Surg 2015;100:390-3.

19. Ogawa M, Hori H, Hirayama M, et al. Anaplastic transformation from papillary thyroid carcinoma with increased serum CA19-9. Pediatr Blood Cancer 2005;45:64-7.

20. Yamaguchi E, Makino Y, Sato T, et al. CA19-9-producing lung metastasis after surgery for papillary thyroid carcinoma: report of a case. Surg Today 2014;44:2157-61. 


\section{References}

21. Prabhu M, Jain D, Gupta SD, et al. Detection of Solitary Axillary Lymph Node Metastases from Hürthle Cell Carcinoma of the Thyroid on (18)F-FDG PET/CT. Nucl Med Mol Imaging 2018;52:389-93.

22. Jung SP, Lee HY, Bae JW, et al. Medullary Thyroid Carcinoma Metastasis to the Breast and Axillary Lymph Nodes. Indian J Surg 2015;77:329-31.

23. Wei BJ, Shen H, Ge F. Management of thyroid carcinoma with metastases in the upper mediastinum and axillary area. Zhonghua Er Bi Yan Hou Tou Jing Wai Ke Za Zhi 2013;48:708-11.

24. Chiofalo MG, Losito NS, Fulciniti F, et al. Axillary node metastasis from differentiated thyroid carcinoma with Hürthle and signet ring cell differentiation. A case of disseminated thyroid cancer with peculiar histologic findings. BMC Cancer 2012;12:55.

25. Elboga U, Kalender E, Yilmaz M, et al. Axillary lymph node metastasis of papillary thyroid carcinoma detected by FDG PET/CT in a thyroglobulin-positive patient with negative whole-body $131 \mathrm{I}$ scan. Clin Nucl Med 2012;37:1120-2.

26. Angeles-Angeles A, Chable-Montero F, Martinez-Benitez $\mathrm{B}$, et al. Unusual metastases of papillary thyroid carcinoma: report of 2 cases. Ann Diagn Pathol 2009;13:189-96.

27. Ers V, Galant C, Malaise J, et al. Axillary lymph node metastasis in recurrence of papillary thyroid carcinoma: a case report. Wien Klin Wochenschr 2006;118:124-7.

28. Lal G, Brennan TV, Hambleton J, et al. Coagulopathy, marantic endocarditis, and cerebrovascular accidents as paraneoplastic features in medullary thyroid cancer-case report and review of the literature. Thyroid 2003;13:601-5.

29. Minagawa A, Iitaka $M$, Suzuki $M$, et al. A case of primary mucoepidermoid carcinoma of the thyroid: molecular evidence of its origin. Clin Endocrinol (Oxf) 2002;57:551-6. 
Table S1 Cases summary of thyroid tumors with axillary lymph node metastasis

\begin{tabular}{|c|c|c|c|c|c|c|c|c|}
\hline Author & $\begin{array}{l}\text { Published } \\
\text { time }\end{array}$ & Country & Age/Sex & $\begin{array}{l}\text { Histopathology } \\
\text { (subtypes) }\end{array}$ & $\begin{array}{l}\text { Presence of } \\
\text { ALNM (yrs) }\end{array}$ & Sites of metastasis & Therapy & Prognosis \\
\hline Present case & & China & $42 / F$ & DSV-PTC & Concurrent & ALN, SCLN & $\begin{array}{l}\text { TTx + ALND + TSH } \\
\text { Suppression + 131RI }\end{array}$ & DFS \\
\hline Prabhu (21) & 2018 & India & $47 / \mathrm{M}$ & FTC (Hürthle Cell) & Recurrence (17) & ALN & $\begin{array}{l}\text { TTx + ALND + TSH } \\
\text { Suppression + 131RI }\end{array}$ & $\mathrm{N} / \mathrm{A}$ \\
\hline Jung (22) & 2015 & South Korea & $49 / F$ & MTC & Recurrence (7) & ALN, Breast & TTx + ALND + MRMT & DFS \\
\hline Ozdemir (18) & 2015 & Turkey & $42 / \mathrm{M}$ & MTC & Recurrence (3) & $\begin{array}{l}\text { ALN, Mediastinum, lung, } \\
\text { cervical vertebra, vessel }\end{array}$ & $\begin{array}{l}\text { TTx + ALND + Target } \\
\text { therapy + Chemotherapy }\end{array}$ & $\mathrm{N} / \mathrm{A}$ \\
\hline \multirow[t]{2}{*}{ Cummings (5) } & 2014 & America & $56 / F$ & PTC (Follicular cell) & Recurrence (8) & ALN, lung, liver, rib & $\begin{array}{l}\text { TTx + ALND + Target } \\
\text { therapy }\end{array}$ & Survival with disease \\
\hline & & America & $58 / \mathrm{M}$ & MTC & $\begin{array}{l}\text { Recurrence } \\
(0.25)\end{array}$ & ALN & $\begin{array}{l}\text { TTx + ALND + Target } \\
\text { therapy }\end{array}$ & Survival with disease \\
\hline Wei (23) & 2013 & China & 46-73/M; F & $\begin{array}{l}\text { PTC ( } 5 \text { cases); } \\
\text { FTC (I case) }\end{array}$ & $\begin{array}{l}\text { Concurrent; } \\
\text { Recurrence }\end{array}$ & $\begin{array}{l}\text { ALN, Mediastinum } \\
\text { ( } 6 \text { cases), Lung ( } 2 \text { cases) }\end{array}$ & $\begin{array}{l}\text { TTx + ALND + TSH } \\
\text { Suppression + 131RI }\end{array}$ & $\begin{array}{l}\text { DFS (5 cases)/ Death } \\
\text { (1 case) }\end{array}$ \\
\hline Chiofalo (24) & 2012 & Italy & $65 / \mathrm{M}$ & $\begin{array}{l}\text { FTC (Hürthle/signet } \\
\text { ring cell) }\end{array}$ & Concurrent & ALN, Bone, Liver & $\begin{array}{l}\text { TTx + ALND + TSH } \\
\text { Suppression + 131RI }\end{array}$ & Survival with disease \\
\hline Elboga (25) & 2012 & Turkey & $64 / \mathrm{M}$ & PTC & Recurrence (14) & ALN, SCLN & TTX + ALND & $\mathrm{N} / \mathrm{A}$ \\
\hline Damle (16) & 2011 & India & $37 / \mathrm{M}$ & PTC (Follicular cell) & Recurrence (2) & ALN, Lung & $\begin{array}{l}\text { TTx + TSH Suppression + } \\
131 \mathrm{RI}\end{array}$ & Survival with disease \\
\hline Krishnamurthy (15) & 2011 & India & $64 / F$ & PTC (Tall cell) & Recurrence (6) & ALN & $\begin{array}{l}\text { TTx + ALND + TSH } \\
\text { Suppression + 131RI }\end{array}$ & DFS \\
\hline Angeles (26) & 2009 & Mexico & $58 / F$ & PTC & Recurrence (17) & ALN, Breast & $\begin{array}{l}\text { TTX + ALND + MRMT + } \\
131 R I\end{array}$ & $\mathrm{~N} / \mathrm{A}$ \\
\hline Kepenekci (17) & 2009 & Turkey & $63 / F$ & PTC & Recurrence (20) & ALN & TTx + ALND & $\mathrm{N} / \mathrm{A}$ \\
\hline Nakayama (14) & 2007 & Japan & $21 / M$ & PTC (Partial poorly) & $\begin{array}{l}\text { Concurrent; } \\
\text { Recurrence (6) }\end{array}$ & ALN, Mediastinum, Lung & $\begin{array}{l}\text { TTx + ALND + TSH } \\
\text { Suppression + 131RI }\end{array}$ & Survival with disease \\
\hline Ers (27) & 2006 & Belgium & $62 / F$ & PTC & Recurrence (5) & ALN, SCLN, Mediastinum & TTx + ALND + 131RI & DFS \\
\hline Koike (4) & 2004 & Japan & $46 / F$ & PTC (Partial poorly) & Recurrence (5) & ALN, Distant metastasis & TTx + ALND + 131RI & $\begin{array}{l}\text { Death (8 months after } \\
\text { recurrence) }\end{array}$ \\
\hline Lal (28) & 2003 & America & $59 / \mathrm{M}$ & MTC & Concurrent & ALN, Mediastinum, Lung & $T T x+A L N D$ & $\begin{array}{l}\text { Death (8 months after } \\
\text { diagnosis) }\end{array}$ \\
\hline Minagawa (29) & 2002 & Japan & $52 / \mathrm{M}$ & MEC & Concurrent & $\begin{array}{l}\text { ALN, Thoracic vertebra, } \\
\text { Lung }\end{array}$ & $\begin{array}{l}\text { Radiotherapy + } \\
\text { Chemotherapy }\end{array}$ & $\begin{array}{l}\text { Death ( } 2 \text { months after } \\
\text { diagnosis) }\end{array}$ \\
\hline Mizukami (6) & 1993 & Japan & $58 / \mathrm{M}$ & MAC & $\begin{array}{l}\text { Recurrence } \\
(0.58)\end{array}$ & ALN & N/A & $\mathrm{N} / \mathrm{A}$ \\
\hline
\end{tabular}

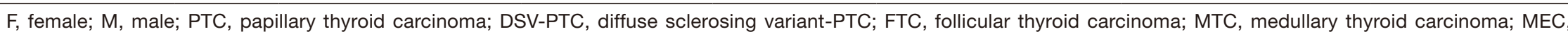

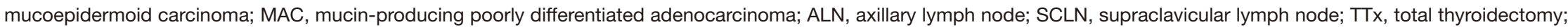

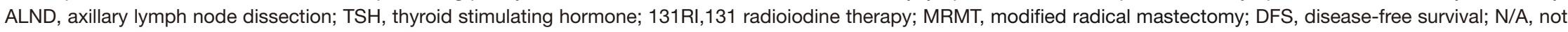
available. 